Article

\title{
Non-Enzymatic Glucose Sensing Using Carbon Quantum Dots Decorated with Copper Oxide Nanoparticles
}

\author{
Houcem Maaoui ${ }^{1,2}$, Florina Teodoresu ${ }^{1}$, Qian Wang ${ }^{1}$, Guo-Hui Pan ${ }^{3}$, Ahmed Addad ${ }^{4}$, \\ Radhouane Chtourou ${ }^{2}$, Sabine Szunerits ${ }^{1}$ and Rabah Boukherroub ${ }^{1, *}$ \\ 1 Institut d'Electronique, de Microélectronique et de Nanotechnologie (IEMN), UMR CNRS8520, \\ Université Lille 1, Avenue Poincaré-BP 60069, 59652 Villeneuve d'Ascq, France; \\ houcemmaaoui@gmail.com (H.M.); fteodorescu@icf.ro (F.T.); qian1.wang@ed.univ-lille1.fr (Q.W.); \\ sabine.szunerits@univ-lille1.fr (S.S.) \\ 2 Département de Physique, Faculté des Sciences de Tunis, Université Tunis-El Manar, 2092 Tunis, Tunisia; \\ radhouane.chtourou@inrst.rnrt.tn \\ 3 State Key Laboratory of Luminescence and Applications, Changchun Institute of Optics, Fine Mechanics and \\ Physics, Chinese Academy of Sciences, 3888 Dong Nanhu Road, 130033 Changchun, China; \\ pangh@ciomp.ac.cn \\ 4 Unité Matériaux et transformations (UMET), UMR CNRS 8207, Université Lille1, Cité Scientifique, \\ 59655 Villeneuve d'Ascq, France; ahmed.addad@univ-lille1.fr \\ * Correspondence: rabah.boukherroub@iemn.univ-lille1.fr; Tel.: +33-362-531-724
}

Academic Editors: Giovanni Sparacino, Andrea Facchinetti and J. Hans DeVries Received: 13 August 2016; Accepted: 12 October 2016; Published: 18 October 2016

\begin{abstract}
Perturbations in glucose homeostasis is critical for human health, as hyperglycemia (defining diabetes) leads to premature death caused by macrovascular and microvascular complications. However, the simple and accurate detection of glucose in the blood at low cost remains a challenging task, although it is of great importance for the diagnosis and therapy of diabetic patients. In this work, carbon quantum dots decorated with copper oxide nanostructures (CQDs $/ \mathrm{Cu}_{2} \mathrm{O}$ ) are prepared by a simple hydrothermal approach, and their potential for electrochemical non-enzymatic glucose sensing is evaluated. The proposed sensor exhibits excellent electrocatalytic activity towards glucose oxidation in alkaline solutions. The glucose sensor is characterized by a wide concentration range from $6 \mu \mathrm{M}$ to $6 \mathrm{mM}$, a sensitivity of $2.9 \pm 0.2 \mu \mathrm{A} \cdot \mu \mathrm{M}^{-1} \cdot \mathrm{cm}^{-2}$, and a detection limit of $6 \mu \mathrm{M}$ at a signal-to-noise ratio $\mathrm{S} / \mathrm{N}=3$. The sensors are successfully applied for glucose determination in human serum samples, demonstrating that the CQDs $/ \mathrm{Cu}_{2} \mathrm{O}$-based glucose sensor satisfies the requirements of complex sample detection with adapted potential for therapeutic diagnostics.
\end{abstract}

Keywords: carbon quantum dots; copper oxide nanoparticles; glucose sensing; non-enzymatic; serum; electrochemistry

\section{Introduction}

Carbon quantum dots (CQDs) have attracted much attention in recent years, due to their outstanding optical and electronic properties [1,2]. Their excellent photoluminescence properties and tunable fluorescence emission, sensitive not only to the size of the carbon particles, but also to the presence of different analytes (e.g., metal ions, anions) have made CQDs widely used as fluorescent labels as well as for chemical sensing applications [1]. Their high stability under strongly basic and acidic conditions and good electrical conductivity have also made them interesting electrocatalytic materials for energy-related applications. Here, oxygen-reduction (ORR) and evolution (OER) reactions are at the center of interest, with the aim of improving the sluggish kinetics and high over-potential 
required to drive oxygen evolution [3,4]. Surprisingly, reports on using CQDs in electrochemical-based sensing applications are still rare [5-7]. CQDs were used in these reports either to promote direct electron transfer between a biomolecule (e.g., hemoglobin) and the electrode surface [5], or for sensing of anticancer drugs such as etoposide [6].

One molecule that is challenging and important to monitor is glucose. An increase in glucose levels is critical for human health, as hyperglycemia (defining diabetes) leads to premature death caused by macrovascular and microvascular complications. The accurate detection of glucose in blood is thus of great importance for the diagnosis and therapy of diabetic patients.

Phenylboronic acid-modified CQDs have been proposed by several groups as a fluorescence-based glucose sensing system [8-10]. A glucose sensing system consisting of fluorescent B-doped CQDs in combination with glucose oxidase was recently developed by Shan et al. [11] as an enzyme-based glucose sensing system. However, the use of CQDs for non-enzymatic glucose sensing has not yet been investigated. Glucose oxidase-based sensors suffer greatly from the poor stability of the enzyme over time, considerably decreasing the shelf-time of these glucose sensors. The development of non-enzymatic sensors [12] based on the direct oxidation of glucose has shown several advantages, such as high sensitivity, good selectivity, and good life shell times over both fluorescence- and enzymatic-based sensors [13-16].

Copper-based electrodes represent an interesting class of materials for the electrocatalytic oxidation of glucose [13-16]. The electrocatalytic activity of these electrodes toward glucose oxidation in alkaline medium is believed to be attributable to the involvement of $\mathrm{Cu}^{2+}$ and $\mathrm{Cu}^{3+}$ surface species. Compared to other catalytic nanostructures based on gold or platinum, $\mathrm{Cu}$ is cheap and abundantly available.

CQDs, on the other hand, are believed to promote electron transfer similar to other carbon-based nanomaterials. The combination of CQDs and octahedral $\mathrm{Cu}_{2} \mathrm{O}$ for non-enzymatic detection of hydrogen peroxide $\left(\mathrm{H}_{2} \mathrm{O}_{2}\right)$ and glucose has recently been reported by Li et al. [17]. The CQDs $/ \mathrm{Cu}_{2} \mathrm{O}$ nanocomposite was prepared using a hydrothermal method and ultrasonic treatment. The developed electrocatalyst exhibited a detection limit of $8.4 \mu \mathrm{M}$ over a 20-4300 $\mu \mathrm{m}$ linear range.

In the present study, we synthesized $\mathrm{Cu}_{2} \mathrm{O}$-decorated CQDs through a simple hydrothermal process with the aim of improving the electrocatalytic activity of the $\mathrm{Cu}_{2} \mathrm{O}$ nanostructures towards glucose sensing in solution and human serum, through their hybridization with CQDs. It is well-known that the hybridization of different nanoparticles on solid substrates limits their aggregation upon immersion in liquid solutions, and thus improves their electro/catalytic activity and stability. The method developed herein for the synthesis of $\mathrm{CQDs} / \mathrm{Cu}_{2} \mathrm{O}$ is cost effective and obeys green chemistry principles, as it takes place in aqueous media.

\section{Experimental Part}

\subsection{Materials}

Fructose, galactose, glucose, ascorbic acid, uric acid, dopamine, sodium hydroxide $(\mathrm{NaOH})$, phenol, sulfuric acid $\left(\mathrm{H}_{2} \mathrm{SO}_{4}\right)$, copper perchlorate $\left(\mathrm{Cu}\left(\mathrm{ClO}_{4}\right)_{2}\right)$, alumina powder $(1,0.3$, and $0.05 \mu \mathrm{m})$, Nafion, and isopropyl alcohol were obtained from Sigma Aldrich (St. Quentin Fallavier, France) and used as received. Human serum was kindly provided by the Centre Hospitalier Universitaire (CHU), Lille, France.

\subsection{Synthesis of Carbon Quantum Dots}

Carbon quantum dots (CQDs) were synthesized by a one-pot method at a relatively low reaction temperature. In a typical procedure, fructose $(500 \mathrm{mM})$ and sodium hydroxide $(500 \mathrm{mM})$ were added to $20 \mathrm{~mL}$ water, the solution was placed in a Teflon-lined stainless steel autoclave and heated at $50{ }^{\circ} \mathrm{C}$ for $1 \mathrm{~h}$. The solution turned from colorless into brown [18]. 


\subsection{Synthesis of Carbon Quantum Dots Loaded with Copper Oxide Nanoparticles (CQDs/Cu $\mathrm{C}_{2}$ )}

Copper perchlorate $(1.35 \mathrm{~g})$ was dissolved in $10 \mathrm{~mL}$ of previously prepared CQDs solution and heated at $80^{\circ} \mathrm{C}$ for $3 \mathrm{~h}$. The formed precipitate was separated by centrifugation, washed with water three times, and annealed at $120^{\circ} \mathrm{C}$ overnight.

\subsection{Synthesis of $\mathrm{Cu}_{2} \mathrm{O}$}

Copper perchlorate $(1.35 \mathrm{~g})$ was dissolved in $10 \mathrm{~mL}$ of sodium hydroxide $(0.5 \mathrm{M})$ aqueous solution and heated at $80^{\circ} \mathrm{C}$ for $3 \mathrm{~h}$. The formed precipitate was separated by centrifugation, washed with water three times, and annealed at $120^{\circ} \mathrm{C}$ overnight.

\subsection{Preparation of $\mathrm{CQDs} / \mathrm{Cu}_{2} \mathrm{O}-$ Modified Electrode}

A bare glassy carbon electrode (GCE), polished before each experiment with alumina powder $(1,0.3$, and $0.05 \mu \mathrm{m})$, was coated by drop casting $4 \mu \mathrm{L}$ of CQDs $/ \mathrm{Cu}_{2} \mathrm{O}$ aqueous solution $(1 \mathrm{mg} / \mathrm{mL})$ onto the electrode and left to dry for $15 \mathrm{~min}$ at $40{ }^{\circ} \mathrm{C}$. The electrode was covered with a Nafion film by drop-casting $30 \mu \mathrm{L}$ of Nafion (1.0 wt.\%) in isopropyl alcohol and dried at $40{ }^{\circ} \mathrm{C}$ for $10 \mathrm{~min}$.

\subsection{Electrochemical Detection of Glucose on $\mathrm{CQDs} / \mathrm{Cu} \mathrm{u}_{2} \mathrm{O}$-Modified GCE}

Electrochemical experiments were performed using an Autolab potentiostat 20 (Eco Chemie, Utrecht, The Netherlands). An Ag/ AgCl (Bioanalytical Systems, Inc., West Lafayette, IN, USA) electrode was used as reference electrode, and platinum wire as counter electrode. Cyclic voltammetry (CV) measurements were performed in aqueous solutions of $0.1 \mathrm{M} \mathrm{NaOH}$ in the absence and presence of glucose.

Chronoamperometric detection of glucose on the CQDs/ $\mathrm{Cu}_{2} \mathrm{O}$-modified GCE ( $3 \mathrm{~mm}$ in diameter) was performed in stirring alkaline solution $(0.1 \mathrm{M} \mathrm{NaOH})$ by applying a constant potential of $+0.55 \mathrm{~V}$ to the working electrode. When the background current became stable (after $100 \mathrm{~s}$ ), a glucose solution was subsequently added and the current was then measured.

\subsection{Determination of Glucose Content in Human Serum Using a Colorimetric Method}

First, a standard calibration curve for glucose was obtained by mixing a freshly prepared phenolic solution ( $1 \mathrm{~mL} ; 5 \mathrm{wt} . \%)$ with $1 \mathrm{~mL}$ aliquot of glucose solution at different concentrations. Concentrated sulphuric acid $(5 \mathrm{~mL})$ was rapidly added to the mixture and left for $20 \mathrm{~min}$ under shaking before $\mathrm{UV} /$ Vis absorption spectra were recorded at $490 \mathrm{~nm}$. Blank solutions were prepared in an identical manner, except that no glucose was added. Human serum $(50 \mu \mathrm{L})$ was diluted five times (volume final: $250 \mu \mathrm{L}$ ) in water and mixed with $250 \mu \mathrm{L}$ freshly prepared phenolic solution $(1 \mathrm{~mL} ; 5 \mathrm{wt} . \%)$. Concentrated sulphuric acid $(1.25 \mathrm{~mL})$ was added, and the mixture was left for 20 min under shaking before a UV/Vis spectrum of the serum sample was recorded.

\subsection{Characterization}

Powder X-ray diffraction (XRD) patterns were collected on a Bruker D8 advance diffractometer (Cu-K $\alpha$ radiation, $1.54056 \AA$, Bruker, Billerica, MA, USA) with an applied voltage of $40 \mathrm{kV}$ and an anode current of $40 \mathrm{~mA}$ in the $2 \theta$ range of $10^{\circ}-80^{\circ}$.

Transmission electron microscopy (TEM) imaging was performed on a FEI Tecnai G2-F20 microscope operating (FEI, Hillsboro, OR, USA) at an accelerating voltage of $200 \mathrm{kV}$.

Micro-Raman spectroscopy measurements were performed on a Horiba Jobin Yvon LabRam HR micro-Raman system combined with a $473 \mathrm{~nm}(1 \mathrm{~mW})$ laser diode as excitation source. Visible light was focused by a $100 \times$ objective. The scattered light was collected by the same objective in backscattering configuration, dispersed by a $1800 \mathrm{~mm}$ focal length monochromator and detected by a charge-coupled device (CCD) camera. 
UV/Vis absorption spectra were recorded using a Perkin Elmer Lambda UV/Vis 950 spectrophotometer (Perkin Elmer, Waltham, MA, USA) in quartz cuvettes with an optical path of $10 \mathrm{~mm}$. The wavelength range was $450-550 \mathrm{~nm}$.

Thermogravimetric analysis (TGA) measurements were carried out in $\mathrm{Al}_{2} \mathrm{O}_{3}$ crucibles in a nitrogen atmosphere at a heating rate of $10{ }^{\circ} \mathrm{C} / \mathrm{min}$ using a TA Instruments Q50 thermogravimetric analyzer.

X-ray photoelectron spectroscopy (XPS) experiments were performed in a $\mathrm{PHl} 5000$ VersaProbe-Scanning ESCA Microprobe (ULVAC-PHI, Chigasaki, Japan) instrument at a base pressure below $5 \times 10^{-9}$ mbar. Monochromatic AlK $\alpha$ radiation was used, and the $X$-ray beam, focused to a diameter of $100 \mu \mathrm{m}$, was scanned on a $250 \times 250 \mu \mathrm{m}$ surface at an operating power of $25 \mathrm{~W}(15 \mathrm{kV})$. Photoelectron survey spectra were acquired using a hemispherical analyzer at pass energy of $117.4 \mathrm{eV}$ with a $0.4 \mathrm{eV}$ energy step. Core-level spectra were acquired at a pass energy of $23.5 \mathrm{eV}$ with a $0.1 \mathrm{eV}$ energy step. All spectra were acquired at $90^{\circ}$ between X-ray source and analyzer and with the use of low energy electrons and low energy argon ions for charge neutralization. After subtraction of the Shirley-type background, the core-level spectra were decomposed into their components with mixed Gaussian-Lorentzian (30:70) shape lines using the CasaXPS software. Quantification calculations were performed using sensitivity factors supplied by PHI. The sample was prepared by casting a concentrated aqueous solution of the material onto silicon substrate followed by drying at $100{ }^{\circ} \mathrm{C}$ for $1 \mathrm{~h}$.

\section{Results}

\subsection{Fabrication of $\mathrm{CQDs} / \mathrm{Cu}_{2} \mathrm{O}$ Electrocatalytic Electrodes for Glucose Sensing}

CQDs were synthesized at $50{ }^{\circ} \mathrm{C}$ via the hydrothermal carbonization method, using fructose as carbon source [18,19]. The obtained CQDs aqueous solution $(1 \mathrm{mg} / \mathrm{mL})$ was mixed with copper perchlorate. Upon heating to $80^{\circ} \mathrm{C}$ for $3 \mathrm{~h}, \mathrm{Cu}_{2} \mathrm{O}$ nanostructures were successfully deposited on the CQDs surface.

Figure 1A depicts the XRD pattern of the as-obtained nanocomposite. Some broad and sharp peaks appeared simultaneously, which were identified to be the reflections of at least two different crystalline phases of $\mathrm{Cu}$ (ICDD No. 65-9026) and $\mathrm{Cu}_{2} \mathrm{O}$ (ICDD No. 78-2076). The corresponding reflection planes of different phases were $43.39^{\circ}$ and $50.67^{\circ}$ for $\mathrm{Cu}(111)$ and $\mathrm{Cu}(200)$, respectively, and $29.5^{\circ}, 36.4^{\circ}$, $42.3^{\circ}, 61.6^{\circ}$, and $73.8^{\circ}$ for $\mathrm{Cu}_{2} \mathrm{O}(110), \mathrm{Cu}_{2} \mathrm{O}(111), \mathrm{Cu}_{2} \mathrm{O}(200), \mathrm{Cu}_{2} \mathrm{O}(220)$, and $\mathrm{Cu}_{2} \mathrm{O}(311)$, respectively. The results suggest that the copper nanoparticles deposited under our experimental conditions consist mostly of copper oxide. In addition, a small peak at $\sim 22.9^{\circ}$ was observed and assigned to the presence of carbon from the CQDs. The results are in accordance with recently reported data on reduced graphene oxide modified with $\mathrm{Cu}_{2} \mathrm{O}$ [20], and $\mathrm{Cu}_{2} \mathrm{O}$-modified multi-walled carbon nanotube nanostructures [21] and CQDs [17].
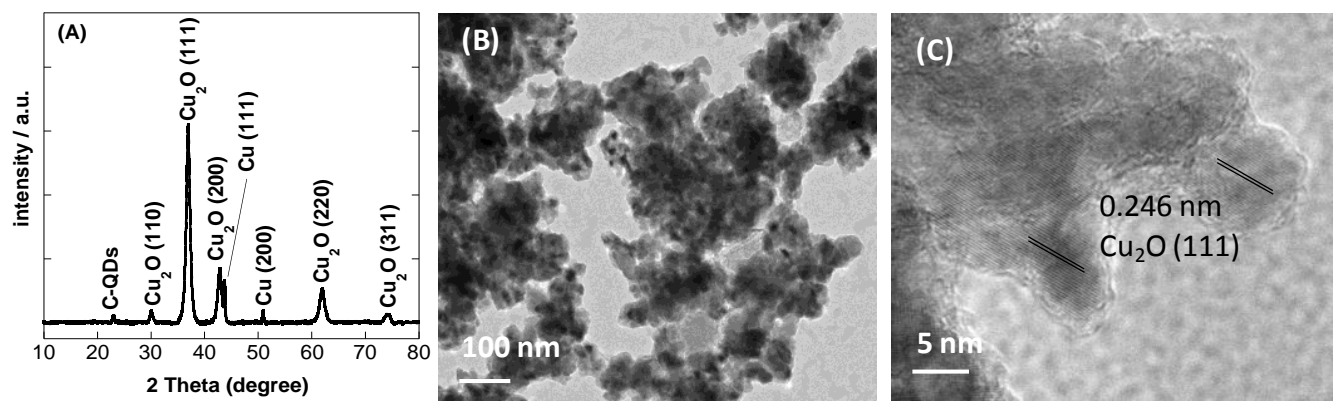

Figure 1. Characterization of carbon quantum dots loaded with copper oxide nanoparticles (CQDs $/ \mathrm{Cu}_{2} \mathrm{O}$ NPs): (A) X-ray powder diffraction (XRD) pattern; (B) transmission electron microscopy (TEM) image; (C) high-resolution TEM (HRTEM) image. 
A low-magnification TEM image (Figure 1B) of the CQDs $/ \mathrm{Cu}_{2} \mathrm{O}$ nanocomposite indicates that the particles are slightly aggregated. In accordance with XRD analysis, the high-resolution TEM image (Figure 1C) identified the presence of the $\mathrm{Cu}_{2} \mathrm{O}$ nanostructures with the lattice fringes of the (111) plane of the $\mathrm{Cu}_{2} \mathrm{O}$ with an interplanar spacing of $0.246 \mathrm{~nm}$.

XPS analysis was further used to obtain more insight into the chemical composition of the as-synthesized CQDs $/ \mathrm{Cu}_{2} \mathrm{O}$ nanocomposite. The XPS survey spectrum shows bands at $285 \mathrm{eV}\left(\mathrm{C}_{1 \mathrm{~s}}\right)$, $531 \mathrm{eV}\left(\mathrm{O}_{1 \mathrm{~s}}\right)$, and bands linked to $\mathrm{Cu}$ at $77 \mathrm{eV}\left(\mathrm{Cu}_{3 \mathrm{~s}}\right), 123 \mathrm{eV}\left(\mathrm{Cu}_{3 \mathrm{p}}\right)$, and $932 \mathrm{eV}\left(\mathrm{Cu}_{2 \mathrm{p}}\right)$ (Figure $\left.2 \mathrm{~A}\right)$ with an overall $\mathrm{Cu}$ content of $4.2 \mathrm{at} \%$. The high-resolution XPS spectrum of $\mathrm{Cu}_{2 \mathrm{p}}$ (Figure $2 \mathrm{~B}$ ) reveals the presence of peaks at 932.7 and $952.6 \mathrm{eV}$ attributed to $\mathrm{Cu}_{2 \mathrm{p} 3 / 2}$ and $\mathrm{Cu}_{2 \mathrm{p} 1 / 2}$, respectively, from $\mathrm{Cu}_{2} \mathrm{O}$.
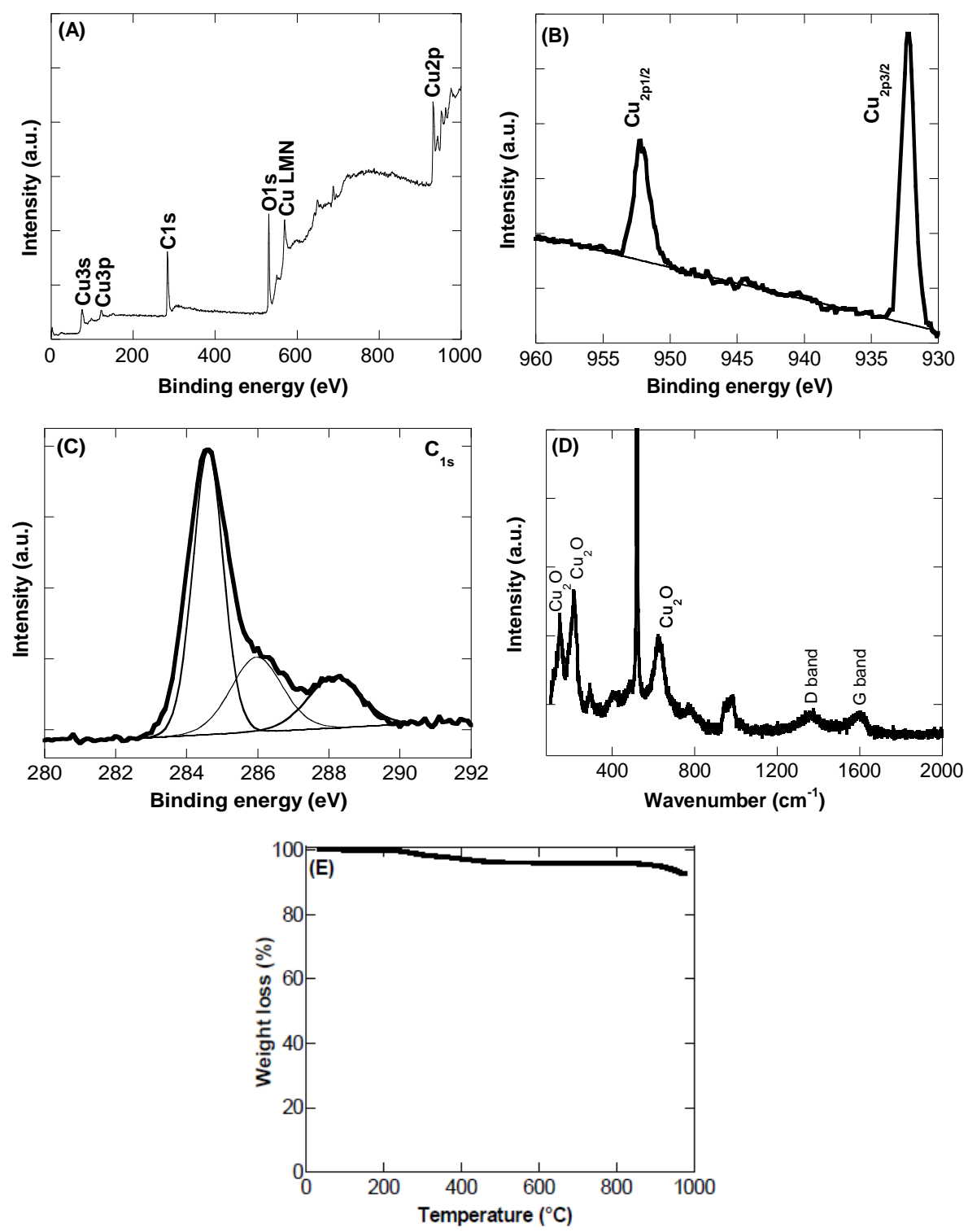

Figure 2. (A) X-ray photoelectron spectroscopy (XPS) survey spectrum; (B) $\mathrm{Cu}_{2 p}$ core level spectrum; (C) $\mathrm{C}_{1 \mathrm{~s}}$ core level spectrum; (D) Raman spectrum; (E) thermogravimetric analysis (TGA) thermogram of $\mathrm{CQDs} / \mathrm{Cu}_{2} \mathrm{O}$ nanocomposite.

The high resolution spectrum of $C_{1 s}$ (Figure $2 \mathrm{C}$ ) exhibits a main peak at $283.6 \mathrm{eV}$ attributed to the C-C bond with $\mathrm{sp}^{2}$ orbital configuration, and further bands at $285.1 \mathrm{eV}$ and $287.3 \mathrm{eV}$ assigned to $\mathrm{sp}^{3}$ hybridized carbons and $\mathrm{C}=\mathrm{O}$ functions, respectively. 
The CQDs $/ \mathrm{Cu}_{2} \mathrm{O}$ was in addition studied by Raman spectroscopy (Figure 2D). Several Raman-active modes are observed. The peaks at 148, 216, and $622 \mathrm{~cm}^{-1}$ are characteristic of $\mathrm{Cu}_{2} \mathrm{O}$ [22]. The presence of CQDs is indicated by the bands at $1356 \mathrm{~cm}^{-1}$ and $1582 \mathrm{~cm}^{-1}$, originating from the G and $\mathrm{D}$ band contributions of the CQDs, respectively, due to the stretching motion of $\mathrm{sp}^{2}$ carbons and from defects in the hexagonal $\mathrm{sp}^{2}$ carbon network.

To gain more insight into the thermal stability of the $\mathrm{CQDs} / \mathrm{Cu}_{2} \mathrm{O}$ nanocomposite, thermogravimetric analysis was performed (Figure 2E). The TGA thermogram shows a small weight loss below $100{ }^{\circ} \mathrm{C}$ due to the desorption of water molecules with a further weight loss of $\approx 4 \%$ between $200-500{ }^{\circ} \mathrm{C}$ attributed to the removal of oxygen-containing functional groups on CQDs. No significant weight loss was observed above $500{ }^{\circ} \mathrm{C}$, indicating the good thermal stability of the nanocomposite.

\subsection{Non-Enzymatic Glucose Sensing}

The electrochemical behavior of a GCE (Figure 3A), a GCE modified with $\mathrm{Cu}_{2} \mathrm{O}$ (Figure 3B), and a GCE modified with CQDs $/ \mathrm{Cu}_{2} \mathrm{O}$ (Figure 3C) in $0.1 \mathrm{M} \mathrm{NaOH}$ aqueous solution in the absence of glucose was evaluated using cyclic voltammetry (CV). The GCE and the GCE/ $\mathrm{Cu}_{2} \mathrm{O}$ electrodes showed no or low electrocatalytic activity for glucose oxidation. The CV of the GCE modified with $\mathrm{CQDs} / \mathrm{Cu}_{2} \mathrm{O}$ comprises several redox peaks. Peak 1 at $-0.35 \mathrm{~V}$ corresponds to the transition of $\mathrm{Cu} 0 / \mathrm{Cu}(\mathrm{I})$, while two processes are involved in peak 2 at $\approx-0.02 \mathrm{~V}$, ascribed to the transitions of $\mathrm{Cu}(0) / \mathrm{Cu}(\mathrm{II})$ and $\mathrm{Cu}(\mathrm{I}) / \mathrm{Cu}(\mathrm{II})$, in accordance with other reports in the literature $[17,23]$. The formation of $\mathrm{Cu}(\mathrm{III})$ is initiated at around $+0.53 \mathrm{~V}$ (peak 3). In the cathodic scan, peaks 4 and 5 at $-0.51 \mathrm{~V}$ and $-0.77 \mathrm{~V}$ correspond to the re-formation of $\mathrm{Cu}(\mathrm{I})$ and $\mathrm{Cu}(0)$, respectively.

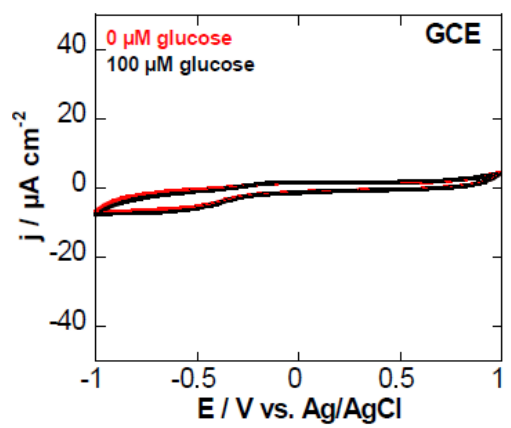

(A)

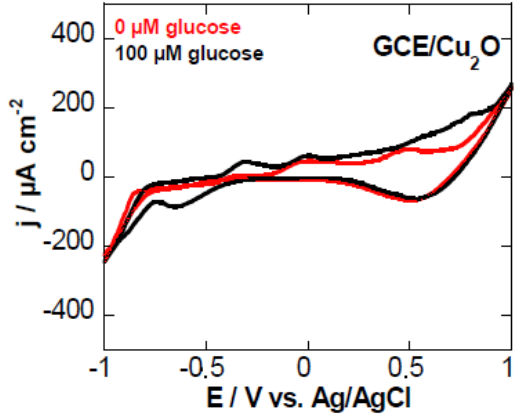

(B)

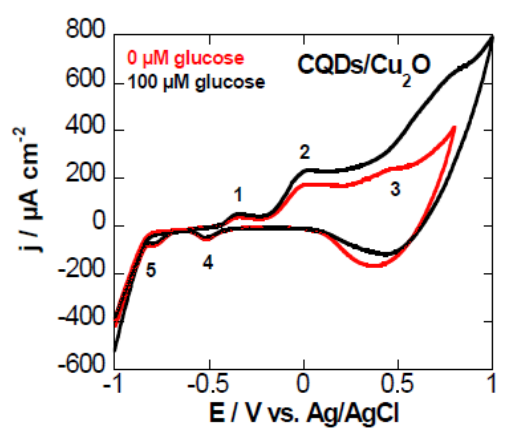

(C)

Figure 3. Cyclic voltammograms of (A) glassy carbon electrode (GCE); (B) GCE/ $\mathrm{Cu}_{2} \mathrm{O}$; and (C) GCE modified with $\mathrm{CQDs} / \mathrm{Cu}_{2} \mathrm{O}$ by drop casting in $0.1 \mathrm{M} \mathrm{NaOH}$ aqueous solution in the absence (red) and presence of glucose (black, $100 \mu \mathrm{M})$.

In order to investigate the applicability of the CQDs/ $\mathrm{Cu}_{2} \mathrm{O}$-modified GC electrode for non-enzymatic glucose sensing, glucose was added to $0.1 \mathrm{M} \mathrm{NaOH}$ aqueous solution, and the 
voltammograms were recorded. A significant increase of the anodic current of peak 3 is obvious. The electrocatalytic oxidation peak is due to the conversation of $\mathrm{Cu}$ (III) to $\mathrm{Cu}(\mathrm{II})$ in basic medium. The $\mathrm{CuO} / \mathrm{Cu}(\mathrm{I})$ couple stays unchanged, ruling out the electrocatalytic reaction with glucose. The mechanism is believed to occur according to the equations below. This mechanism also highlights the importance of working under basic conditions. At neutral pH, no electrocatalysis takes place.

$$
\begin{aligned}
& \mathrm{CQDs} / \mathrm{Cu}_{2} \mathrm{O}+\mathrm{OH}^{-} \rightarrow \mathrm{CQDs} / \mathrm{CuOOH}+\mathrm{e}^{-} \\
& \mathrm{CQDs} / \mathrm{Cu}_{2} \mathrm{O}+\mathrm{H}_{2} \mathrm{O}+2 \mathrm{OH}^{-} \rightarrow \mathrm{CQDs} / \mathrm{Cu}(\mathrm{OH})_{4}{ }^{-}+\mathrm{e}^{-} \\
& \mathrm{Cu}^{3+}+\text { glucose }+\mathrm{e}^{-} \rightarrow \mathrm{Cu}^{2+}+\text { gluconolactone }
\end{aligned}
$$

The electrocatalytic response of the CQDs/ $\mathrm{Cu}_{2} \mathrm{O}$-modified GCE to glucose under basic conditions was further investigated by amperometric current-time response upon successive addition of different concentrations of glucose. Figure $4 \mathrm{~A}$ displays the amperometric response of the modified electrode at an applied potential of $+0.55 \mathrm{~V}$ vs. $\mathrm{Ag} / \mathrm{AgCl}$ upon successive addition of glucose $(100 \mu \mathrm{M})$ up to $500 \mu \mathrm{M}$. The oxidation current increased gradually upon the injection of increasing concentrations of glucose into the $\mathrm{NaOH}$ solution, and reached the maximum steady state current within $\approx 10$ s. Figure $4 \mathrm{~B}$ depicts the corresponding calibration curve of the current response versus glucose concentration. From the calibration curve, linearity $\left(\mathrm{R}^{2}=0.999\right)$ over a wide concentration range $(3 \mu \mathrm{M}-8 \mathrm{mM})$ with a slope of $0.012 \pm 2.95 \mathrm{~mA} \cdot \mathrm{mM}^{-1} \cdot \mathrm{cm}^{-2}$ were determined. With a current noise of $\approx 0.4 \mu \mathrm{A}$, a detection limit of $\approx 6 \mu \mathrm{M}$ was reached at a signal-to-noise ratio $(\mathrm{S} / \mathrm{N})=3$. The value is comparable to the detection limits reported for other glucose sensors based on electrochemical (EC) techniques (Table 1). However, the sensitivity of the sensor is considerably improved using this $\mathrm{CQDs} / \mathrm{Cu}_{2} \mathrm{O}$ matrix.

To evaluate the effect of potential interfering compounds commonly found in biological fluids on the electrochemical detection of glucose, the current response of a glucose solution without and in the presence of ascorbic acid, uric acid, or dopamine of the same concentration was determined. To evaluate the selectivity towards glucose, other carbohydrate derivatives (such as fructose and galactose) were also examined. Figure 5A shows that no significant current increase was detected upon the addition of ascorbic acid, uric acid, or dopamine, suggesting that these species do not interfere with glucose detection under our experimental conditions. Similarly, no obvious response upon the addition of different interfering carbohydrate molecules was observed, indicating a good selectivity toward glucose detection.
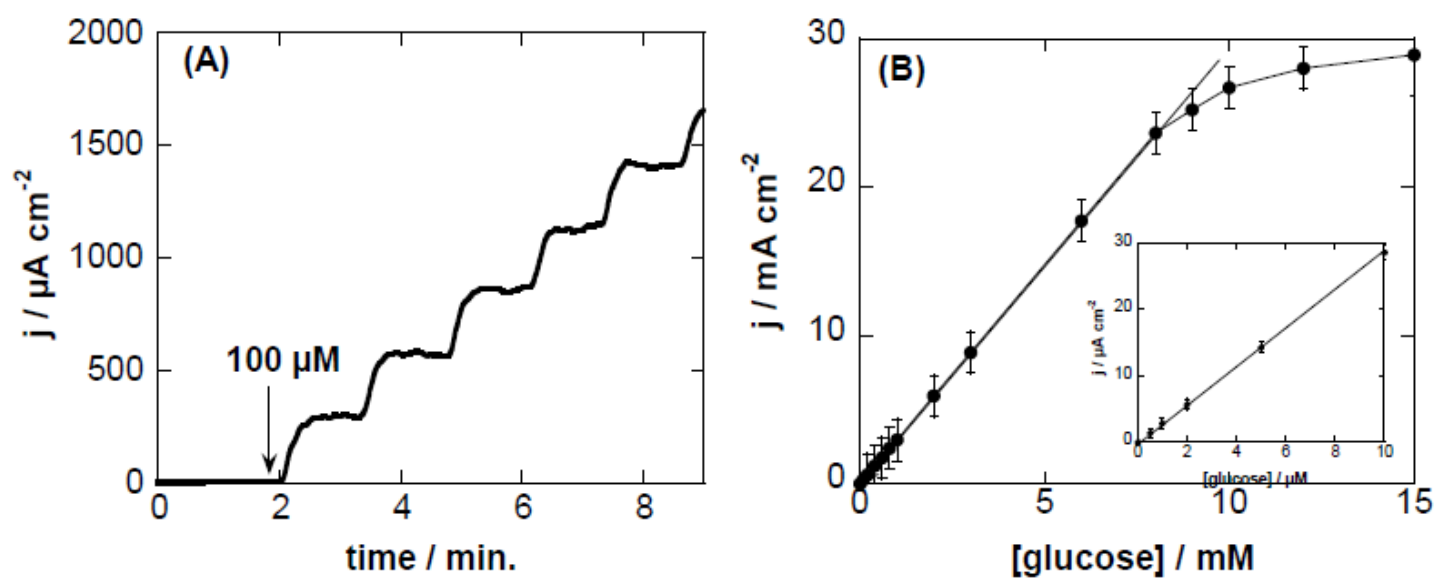

Figure 4. (A) Amperometric response curve of $\mathrm{CQDs} / \mathrm{Cu}_{2} \mathrm{O}$-modified GCE polarized at $+0.55 \mathrm{~V}$ vs. $\mathrm{Ag} / \mathrm{AgCl}$ upon successive additions of glucose $(100 \mu \mathrm{M})$ in $0.1 \mathrm{M} \mathrm{NaOH}$ (up to a total of $500 \mu \mathrm{M}$ ); (B) Calibration curve for $\mathrm{CQDs} / \mathrm{Cu}_{2} \mathrm{O}$-modified GCE electrodes for the determination of glucose. The inset corresponds to a calibration curve for glucose concentrations of $0-10 \mu \mathrm{M}$. 
Table 1. Comparison of the analytical performance of other $\mathrm{Cu}$-based non-enzymatic glucose sensors, as well as CQDs sensors. EC: electrochemical; LOD: limit of detection; rGO: reduced graphene oxide; MWCNTs: multi-walled carbon nanotubes.

\begin{tabular}{|c|c|c|c|c|c|c|}
\hline Sensing Material & $\begin{array}{l}\text { Detection } \\
\text { Method }\end{array}$ & Solution & $\begin{array}{c}\text { Sensitivity } \\
\left(\mu \mathrm{A} \cdot \mu \mathbf{M}^{-1} \cdot \mathrm{cm}^{-2}\right)\end{array}$ & $\begin{array}{c}\text { Linear } \\
\text { Range }(\mu \mathrm{M})\end{array}$ & LOD $(\mu \mathrm{M})$ & Reference \\
\hline B-doped CQDs & fluorescence & Water (pH 7.4) & - & $8-80$ & 8 & [11] \\
\hline Boronic acid-CQDs & fluorescence & Water (pH 7.4) & - & $0.1-20,000$ & 100 & [10] \\
\hline Boronic-acid-CQDs & fluorescence & Water (pH 7.4) & - & 9-900 & 1.5 & [9] \\
\hline $\mathrm{Cu}$ NPs/MWCNTs & $\mathrm{EC}$ & $\mathrm{NaOH}(20 \mathrm{mM})$ & 0.27 & $10-300$ & 0.5 & [24] \\
\hline $\mathrm{Cu} \mathrm{NPs} / \mathrm{rGO}$ & $\mathrm{EC}$ & $\mathrm{NaOH}(100 \mathrm{mM})$ & 0.447 & $100-1200$ & 3.4 & [14] \\
\hline $\mathrm{Cu}_{2} \mathrm{O} / \mathrm{SMWNTs}$ & $\mathrm{EC}$ & $\mathrm{NaOH}(100 \mathrm{mM})$ & 2.1 & $0.5-2500$ & 0.2 & [21] \\
\hline $\mathrm{Cu}_{2} \mathrm{O} / \mathrm{CQDs}$ & EC & $\mathrm{NaOH}(100 \mathrm{mM})$ & 0.298 & $20-4300$ & 8.4 & [17] \\
\hline $\begin{array}{l}\text { Graphene wrapped } \\
\qquad \mathrm{Cu}_{2} \mathrm{O}\end{array}$ & EC & KOH (100 mM) & 0.285 & $300-3300$ & 3.3 & [25] \\
\hline $\mathrm{CQDs} / \mathrm{Cu}_{2} \mathrm{O}$ & EC & $0.1 \mathrm{M} \mathrm{NaOH}$ & $2.95 \pm 0.2$ & $1.3-6000$ & 6 & This work \\
\hline
\end{tabular}
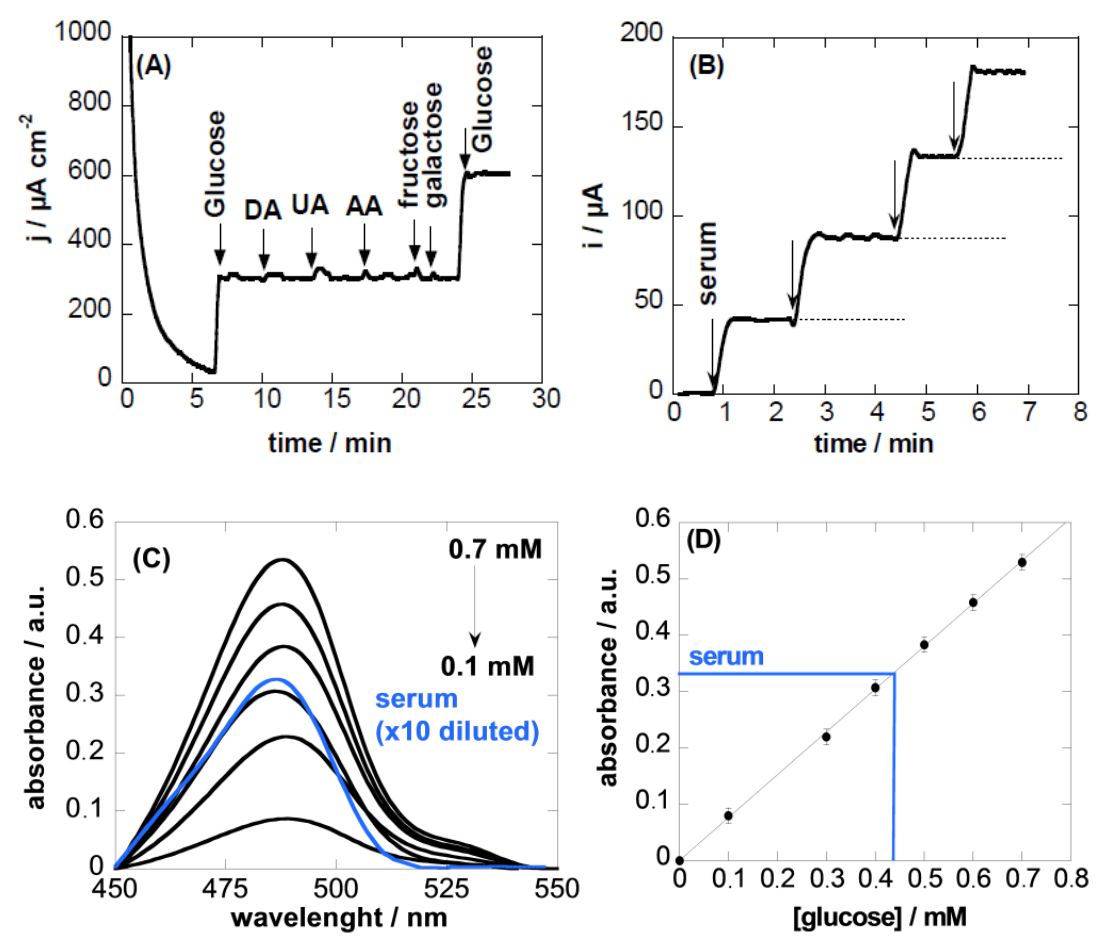

Figure 5. (A) Interference test of CQDs/ $\mathrm{Cu}_{2} \mathrm{O}$-modified GCE electrode in $0.1 \mathrm{M} \mathrm{NaOH}$ at $+0.55 \mathrm{~V}$ with $100 \mu \mathrm{M}$ glucose in the presence $500 \mu \mathrm{M}$ dopamine (DA), uric acid (UA), ascorbic acid (AA), fructose, galactose; (B) current response to the addition of serum; (C) UV/Vis spectra of different concentrations of glucose as well as of the serum samples (ten times diluted) together with calibration curve (D).

The reproducibility of the electrode fabrication and use for glucose sensing is expressed in terms of relative standard deviation, which is found to be $5.3 \%$ at a glucose concentration of $1 \mathrm{mM}$. The long-term stability of the electrode was estimated after storage in a refrigerator at $4{ }^{\circ} \mathrm{C}$ for two months. The sensor retained about $90 \%$ of its initial current response to $1 \mathrm{mM}$ glucose in $0.1 \mathrm{M} \mathrm{NaOH}$ aqueous solution at $+0.55 \mathrm{~V}$, suggesting a good stability of the electrode.

\subsection{Sensing in Real Samples}

A major concern inherent to any detection assay for biologically-relevant analytes in human serum is the possibility of background interferences. In order to evaluate the validity of the proposed 
glucose sensing electrode, serum samples of diabetic and healthy patients were analyzed with our sensor. Figure 5B shows the current response to $0.1 \mathrm{M} \mathrm{NaOH}(2 \mathrm{~mL})$ upon the successive addition of undiluted serum. Using the calibration curve in Figure 4B, a glucose concentration of $4.2 \pm 0.3 \mathrm{mM}$ was determined. The concentration of glucose in human serum samples determined with the CQDs $/ \mathrm{Cu}_{2} \mathrm{O}$-modified GC electrode was compared to the concentration determined spectrophotometrically based on the phenol-sulfuric acid colorimetric method, well-established for analysis of carbohydrates. The UV/Vis absorption maximum obtained from the addition of $10 \mu \mathrm{L}$ undiluted human serum solution into $1 \mathrm{~mL}$ phenol-sulfuric solution (10 times dilution) was compared to that of a calibration curve for glucose established under the same conditions (Figure 5C). The concentration of glucose in the human serum sample was determined to be $4.4 \pm 0.3 \mathrm{mM}$.

\section{Conclusions}

In summary, this work demonstrated the interest of $\mathrm{CQDs} / \mathrm{Cu}_{2} \mathrm{O}$-modified GC electrodes for sensing. The electrocatalytic activity of the material allowed for the detection of glucose in a non-enzymatic manner under basic conditions. While the obtained limit of detection is comparable to other carbon-based/Cu decorated nanomatrices, the $\mathrm{CQDs} / \mathrm{Cu}_{2} \mathrm{O}$ matrix shows enhanced sensitivity and offers a facile and low-cost material for glucose sensing. Moreover, the utility of the sensors for the investigation of real samples was demonstrated upon the determination of glucose in the serum of patients. This work might open up new opportunities for the use of CQDs-based composites not only for fluorescence, but also for electrochemical detection of various analytes in complex media.

Acknowledgments: R.B. and S.S. gratefully acknowledge financial support from the Centre National de la Recherche Scientifique (CNRS), the Lille1 University, the Hauts-de-France region and the CPER Photonics for Society. S.S thanks the Institut Universitaire de France (IUF) for financial support. G.-H.P. is grateful to financial support from National Natural Science Foundation of China (Grants No. 51202019 and 51402284), the Development Plan of Science and Technology of Jilin province (20150520022JH), and the Prior Sci-tech Program of Innovation and Entrepreneurship of Oversea Chinese Talent of Jilin province.

Author Contributions: Houcem Maaoui synthesized materials and performed experiments, Florina Teodorescu helped in glucose sensing experiments, Qian Wang performed electrochemical measurements, Guo-Hui Pan performed XRD analysis, Ahmed Addad performed TEM analysis, Sabine Szunerits performed XPS analysis, Radhouane Chtourou participated in paper writing, Rabah Boukherroub wrote the paper and coordinated the work.

Conflicts of Interest: The authors declare no conflict of interest.

\section{References}

1. Lim, S.Y.; Gao, Z. Carbon quantum dots and their applications. Chem. Soc. Rev. 2015, 44, 362-381. [CrossRef] [PubMed]

2. Wang, Y.; Hu, A. Carbon quantum dots: Synthesis, properties and applications. J. Mater. Chem. C 2014, 2, 6921-6939. [CrossRef]

3. Li, Y.; Zhao, Y.; Cheng, H.H.; Hu, Y.; Shi, G.Q.; Dai, L.M.; Qu, L.T. Nitrogen-doped graphene quantum dots with oxygen-rich functional groups. J. Am. Chem. Soc. 2012, 134, 15-18. [CrossRef] [PubMed]

4. Tang, D.; Liu, J.; Wu, X.Y.; Liu, R.H.; Ha, X.; Ha, Y.Z.; Huang, H.; Liu, Y.; Kang, Z.H. Carbon quantum dot/NiFe layered double-hydroxide composite as a highly efficient electrocatalyst for water oxidation. ACS Appl. Mater. Interfaces 2014, 6, 7918-7925. [CrossRef] [PubMed]

5. Lu, Q.; Hu, S.S.; Pang, D.W.; He, Z.K. Direct electrochemistry and electrocatalysis with hemoglobin in water-soluble quantum dots film on glassy carbon electrode. Chem. Commun. 2005, 20, 2584-2585. [CrossRef] [PubMed]

6. Nguyen, H.V.; Richtera, L.; Moulick, A.; Xhachiu, K.; Kudr, J.; Cernei, N.; Polanska, H.; Heger, Z.; Masarik, M.; Kopel, P.; et al. Electrochemical sensing of etoposide using carbon quantum dot modified carbon electrode. Analyst 2016, 141, 2665-2675. [CrossRef] [PubMed]

7. Lim, C.S.; Hola, K.; Ambrosi, A.; Zboril, R.; Pumera, M. Graphene and carbon quantum dots electrochemistry. Electrochem. Commun. 2015, 52, 75-79. [CrossRef] 
8. Qu, Z.B.; Zhou, X.G.; Gu, L.; Lan, R.M.; Sun, D.D.; Yu, D.J.; Shi, G.Y. Boronic acid functionalized graphene quantum dots as a fluorescent probe for selective and sensitive glucose determination in microdialysate. Chem. Commun. 2013, 49, 9830-9835. [CrossRef] [PubMed]

9. Shen, P.; Xia, Y. Synthesis-modification integration: One-step fabrication of boronic-acid functionalized carbon dots for fluorescent blood sugar sensing. Anal. Chem. 2014, 86, 5323-5329. [CrossRef] [PubMed]

10. Wang, H.; Yi, J.; Velado, D.; Yu, Y.; Zhou, S. Immobilization of carbon dots in molecularly imprinted microgels for optical sensing of glucose at physiological pH. ACS Appl. Mater. Interfaces 2015, 7, 15735-15745. [CrossRef] [PubMed]

11. Shan, X.; Chai, L.; Ma, J.; Qian, Z.; Chen, J.; Feng, H. B-doped carbon quantum dots as a sensitive fluorescence probe for hydrogen peroxide and glucose sensing. Analyst 2014, 139, 2322-2325. [CrossRef] [PubMed]

12. Toghill, K.E.; Compton, R.G. Electrochemical non-enzymatic glucose sensors: A perspective and an evaluation. Int. J. Electrochem. Sci. 2010, 5, 1246-1301.

13. Luo, M.Z.; Baldwin, R.P. Characterization of carbohydrate oxidation at copper electrodes. J. Electroanal. Chem. 1995, 387, 87-94. [CrossRef]

14. Wang, Q.; Li, M.; Szunerits, S.; Boukherroub, R. Preparation of reduced graphene oxide-Cu composites through electrophoretic deposition: application for nonenzyamtic glucose sensing. RCS Adv. 2015, 5, 15861-15869. [CrossRef]

15. Chen, Q.; Zhang, L.; Chen, G. Facile preparation of graphene-copper nanoparticle composite by in situ chemical reduction for electrochemical sensing of carbohydrates. Anal. Chem. 2012, 84, 171-178. [CrossRef] [PubMed]

16. Jiang, D.; Liu, Q.; Wang, K.; Qian, J.; Dong, X.; Yang, Z.; Du, X.; Qiu, B. Enhanced non-enzymatic glucose sensing based on copper nanoparticles decorated nitrogen-doped graphene. Biosens. Bioelectron. 2014, 54, 273-278. [CrossRef] [PubMed]

17. Li, Y.; Zhong, Y.; Zhang, Y.; Weng, W.; Li, S. Carbon quantum dots/octahedral $\mathrm{Cu}_{2} \mathrm{O}$ nanocomposite for non-enzyaltic glucose and hydrogen peroxide amperometric sensors. Sens. Actuators B Chem. 2015, 206, 735-743. [CrossRef]

18. Bozetine, H.; Wang, Q.; Barras, A.; Li, M.; Hadjersi, T.; Szunerits, S.; Boukherroub, R. Green chemistry approach for the synthesis of $\mathrm{ZnO}$-carbon dots nanocomposites with good photocatalytic properties. J. Colloid Interface Sci. 2016, 465, 286-294. [CrossRef] [PubMed]

19. Li, Y.; Zhong, X.; Rider, A.E.; Furman, S.A.; Ostrikov, K. Fast, energy-efficient synthesis of luminescent carbon quantum dots. Green Chem. 2014, 16, 2566-2570. [CrossRef]

20. An, X.; Li, K.; Tang, J. Cu $\mathrm{Cu}_{2} \mathrm{O}$ reduced graphene oxide composites for the photocatalytic conversion of $\mathrm{CO}_{2}$. ChemSusChem 2014, 7, 1086-1093. [CrossRef] [PubMed]

21. Zhou, X.; Nie, H.; Yao, Z.; Dong, Y.; Yang, Z.; Huang, S. Facile synthesis of nanospindle-like $\mathrm{Cu}_{2} \mathrm{O} /$ straight multi-walled carbon nanotube hybrid nanostructures and their application in enzyme-free glucose sensing. Sens. Actuators B Chem. 2012, 168, 1-7. [CrossRef]

22. Yu, W.; Han, M.; Jiang, K.; Duan, Z.; Li, Y.; Hu, Z.; Chu, J. Enhanced Fröhlich interaction of semiconductor cuprous oxide films determined by temperature-dependent Raman scattering and spectral transmittance. J. Raman Spectrosc. 2013, 44, 142-146. [CrossRef]

23. Zhang, Y.; Su, L.; Manuzzi, D.; Valdés Espinosa de los Monteros, H.; Jia, W.; Huo, D.; Hou, C.; Lei, Y. Ultrasensitive and selective non-enzymatic glucose detection using copper nanowires. Biosens. Bioelectron. 2012, 31, 426-432. [CrossRef] [PubMed]

24. Wu, H.-X.; Cao, W.-M.; Li, Y.; Liu, G.; Wen, Y.; Yang, H.-F.; Yang, S.-P. In situ growth of copper nanoparticles on multiwalled carbon nanotubes and their application as non-enzymatic glucose sensor materials. Electrochim. Acta 2010, 55, 3734-3740. [CrossRef]

25. Liu, M.; Liu, R.; Chen, W. Graphene wrapped $\mathrm{Cu}_{2} \mathrm{O}$ nanocubes: Non-enzymatic electrochemical sensors for the detection of glucose and hydrogen peroxide with enhanced stability. Biosens. Bioelectron. 2013, 45, 206-212. [CrossRef] [PubMed]

(C) 2016 by the authors; licensee MDPI, Basel, Switzerland. This article is an open access article distributed under the terms and conditions of the Creative Commons Attribution (CC-BY) license (http://creativecommons.org/licenses/by/4.0/). 